\title{
An Unfinished Manifesto for Stereotomy 2.0
}

\author{
Giuseppe Fallacara $^{1}$ - Maurizio Barberio ${ }^{1}$ (D
}

\begin{abstract}
The aim of the article is to describe the historical background and the birth of a relatively new discipline consisting in the digital evolution of classical stereotomy. "Stereotomy 1.0" comprises the early development of the discipline primarily related to stonecutting. The new discipline, "Stereotomy 2.0 " goes beyond this early concept to embrace contemporary design paradigms and materials. It is described in an "Unfinished Manifesto", which describes its fundamental theoretical principles, understood as a new didactic comprehensive approach for the schools of architecture and a new design process useful for contemporary architectural design. Each point of the Manifesto is described in a short paragraph and shows the most important theoretical nodes of the renewed discipline. The various points are then exemplified by the experimental projects presented in the final part of the article.
\end{abstract}

Keywords Stereotomy $2.0 \cdot$ Stereotomy $\cdot$ Digital stereotomy $\cdot$ Stereotomic design stone architecture - Digital fabrication - Topological interlocking blocks

Maurizio Barberio

mauriziobarberio@hotmail.it; mb@newfundamentals.it

Giuseppe Fallacara

giuseppe.fallacara@poliba.it

1 Dipartimento di Scienze dell'Ingegneria e dell'Architettura, Politecnico di Bari, Via Orabona 4, 70125 Bari, Italy 


\section{Introduction}

This article is a reasoned summary of the research on stereotomy, conducted by the first author, Giuseppe Fallacara, for over 15 years now, starting from his doctoral thesis (Fallacara 2003), through the publication of numerous monographs and scientific articles, and his experiments with the design and construction of numerous demonstration prototypes. The research carried out in the past years focused on two aspects: on the one hand, the rediscovery and in-depth analysis of historical sources, treatises, manuals and monuments; on the other, the desire to experiment with new intrinsic design potentials of the discipline in favour of its use in contemporary architecture.

On these methodological axes, the research has been enriched with notable theoretical-applicative contributions by many other researchers who participated in the research and especially by many companies and training institutes that have supported and contributed greatly to the design and constructive experimentation. Without the contribution of those companies the work done up to now, in its theoretical-applicative articulation, would surely not have been possible and in any case would have to be considered inconclusive as a field of research that is constantly evolving. Part of the research work carried out in recent years has been included in the doctoral thesis of the second author, Barberio (2018), which focused on the definition of the new frontiers of stone stereotomic architecture, through the use of the most recent parametric-computational design softwares, and digital/ robotic manufacturing tools.

The theoretical reflections that accompanied the design and construction experiments carried out in unison by the two authors in recent years, led to the definition of an "Unfinished Manifesto" of "Stereotomy 2.0", a digital evolution of classical stereotomy composed of ten points. The Manifesto describes the fundamental theoretical points underlying the "Stereotomic Design", understood as a new didactic discipline for schools of architecture and as a new design process useful for contemporary architectural design. In what follows, each point of the Manifesto is described in a short paragraph and shows the most important theoretical nodes of the renewed discipline. The various points are then exemplified by the experimental built projects presented in the final part of the article as support for the theoretical framework presented.

\section{The Spiritual Foundation of Stereotomy}

Observing the current research on the construction of form or form finding speculations, we notice a great attention to curved space and vaulted pavilions. We might state that there is a constant and innate, perhaps unconscious, desire to represent the celestial vault, as the ancient idea of sky underlies the design of vaulted spaces of the sacred spaces of monuments and cathedrals. There is a constant relationship between the representation of the ethereal form of the sky and the resistance of the materials available on earth. Since the classical era, the effort to 
determine the shape of the universe been a main research topic, and it represents one of the largest areas of man's intellectual interest. Since ancient times, men have looked at the sky and wondered about its origin, its ending and the space-time dimension. Here we aim to demonstrate the fundamental relation between the stereotomy and the idea of the shape of the heavens, by analysing in detail the etymology of stereotomy itself. The term "stereotomy" in architectural literature was used for the first time in 1644, in the Examen des oeuvres de Sr. Desargues by Curabelle (1644). It is useful to note that the term stereotomy appeared here without the support of a specific terminological or a comprehensive graphic description for the first time. It was solely used to refer to the sections of solids, probably deriving from the union of two Greek words: $\Sigma \tau \varepsilon \rho \varepsilon o ́ \varsigma$, "solid", and To $\mu \eta$, "cut".

Even if this is well known among the scholars involved in the discipline, two points are still unclear. First, what motivations moved Curabelle to create the Greek-derived term "stereotomy", referring to a methodology that was already well-known with the French expression art du trait géométrique? Second, is it possible to find references and/or cultural influences related with the use of that new term? One of the interesting questions is: how did Curabelle, a "simple" mason, coin the Greek term stereotomy?

Our hypothesis is that the conceptual meaning of geometry within the Christian doctrine, thus the measurement or the shape of the Earth, was the spiritual reference that may have influenced Curabelle's use of the term stereotomy. A well-known Christian representation of the world was ideated in the sixth century, by Cosmas Indicopleustes, a Byzantine merchant and geographer, who later became a monk. The most ancient transcriptions of such work date back to the eleventh century. Thinking about the biblical tabernacle, Cosmas, in his Christian Topography (11th c.), asserted that the cosmos was a rectangle with an arch overhanging the flat pavement of the Earth. According to Cosmas's model, the curved vault was hidden by the veil of the firmament, called "stereoma". The world we are living in (the oecumene), extended beneath the stereoma and rested on the ocean. The reconstruction of Cosmas Indicopleuste's world-tabernacle by Eco (2000) (Fig. 1), comprehensively represents the whole scene: the parallelepiped of the tabernacle containing the flat earth and a huge mountain, and a barrel vault surrounding the parallelepiped, in which the starry sky (called stereoma or, in Latin, firmamentum) was developed. Moses' biblical tabernacle was the original reference for Cosmas's representation, which became, in turn, the inspirational model for the churches with a longitudinal nave and a barrel vault with a coffered intrados (Fallacara 2017: 7).

According to Cosma's tabernacle model, the curved vault was hidden by the veil of stereoma. Furthermore, it is fundamental to emphasise the strong etymological connection between the terms "stereotomy" and "stereoma", both derived from the Greek word "astra" (fixed star) and recalling somehow a "vaulted space": the first one (stereotomy) referring to a real dome, and the second one (stereoma) to the vault of perfect and geometric heavens. When Curabelle lived, the main source of knowledge derived from the Christian perceptions based on the biblical tradition in Greek, the basis of the term stereotomy. We can thus affirm that an important paradox took place: the misinterpretation of the shape of the cosmos (the error of the 


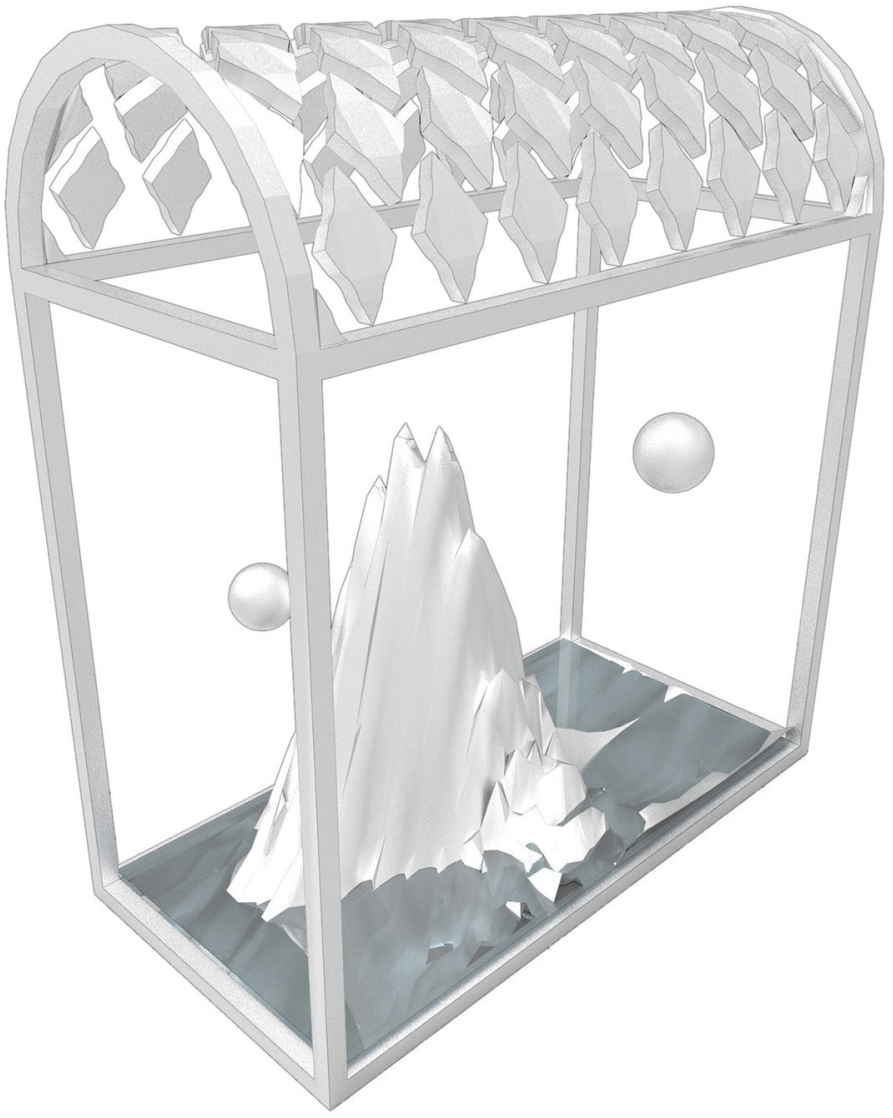

Fig. $13 D$ reconstruction of the Cosmas Indicopleustes's tabernacle by Giuseppe Fallacara based on the Pl. 82.10, ff. 95v-96r of Topographia Christiana, XI sec., Biblioteca Medicea Laurenziana, Florence, Italy. Image available online: https://brunelleschi.imss.fi.it/galileopalazzostrozzi/object/CosmasIndicop leustesTopographiaChristiana.html

flat earth/oecumene with the dome of the sky) has formed the basis of the realization of all the amazing architectural constructions aiming to recall it (Fallacara 2017: 9).

While the description of the world was based on a manmade image (a tabernacle and a barrel vault), the one investigating the scientific stonecutting method and the realization of vaults and domes, will be based on a metaphysical concept.

Although we cannot be totally sure, it is very likely that in 1644 Curabelle was aware of the spherical shape of the earth, even if it was not widespread knowledge among all social classes yet. However, it is important to highlight that the text of Cosmas Indicopleustes, written in ancient Greek, was introduced to the Western world only at the very end of the seventeenth century. In that period, the belief that the sky was composed of perfect geometric shapes, referring to the alleged position of the fixed stars, and according to a divine program, was challenged by Galileo Galilei (Torrini 1993). The demonstration of the "random" disposition of the stars, opposed to the idea of a celestial geometry, divine and thus perfect, paved the way 
for new approaches to the study of the shape of the universe that no longer contemplated the "fixity" of Euclidean geometry (Fallacara 2017: 9).

Vaulted space has always represented the ideal ambit in which to operate the more sophisticated and complex reflections on the construction of architecture. This is particularly true for the stereotomic architecture. According to Philibert de l'Orme, the architectural production based on the use of stereotomy has constantly focused on the paradox that could ensure that heavy stonework seems to be an aerial structure, "suspendue en l'air" (suspended in the air). Despite the heaviness of the stones with which they were built, such domed and vaulted spaces appear to defy gravity, resulting in dynamic and antistatic architecture derived from the airy, light and ethereal sky. The dialectic contamination between the heaviness of the stone and the lightness of the aerial or pneumatic forms of the starry sky, can be considered as one of the cornerstone of a conceptual foundation for the updating of stereotomy and stereotomic design. Although the ideas set forth here are hypothetical because of linguistic difficulties, we believe it is possible to state that our interpretation is very plausible. In this sense the correlation between the celestial vault and stereotomy is founded in the undisputed faith that animated the builders of churches during the years in which the stereotomy was used. The stone vaults become the manmade representation of the divine universe.

\section{Stereotomy 1.0}

The practices known as the "art du trait géométrique", although probably used in practice, were formalised in theory by Philibert de l'Orme with the publication of Le Premier Tome de l'Architecture in 1576 (Fallacara 2007: 36). The introduction of trait géométrique was therefore indispensable precisely in those cases in which the complexity of the geometries to be constructed made it necessary to control them during the design phase, without delegating the control of the operations to be carried out by the stonemasons and only during the construction phase (Trevisan 2009: 526). Alongside the resolution of the practical aspects of the construction, de l'Orme's cultural intent was to carry the Gothic building culture forward to the new Renaissance style with a strong Italian influence (Pérouse de Montclos 2001: 93-94). His operation is fundamental for our discussion: with his theoretical work, a central importance is returned to the figure of the architect, called upon to know not only the rules of composition and design, but also those of construction and practice, so that they were no longer the exclusive prerogative of master masons. To do this, it was essential that the architect be aware of the whole construction process. Hence the need to master advanced methods (such as the trait), not only as a form of geometric virtuosity applied to architecture, but above all to solve real constructive problems; a procedure for determining the exact shape of the voussoirs of the vaulted systems and, consequently, of the entire architecture (Trevisan 2011: 9).

Starting from the treatise of de l'Orme, various treatises on stereotomy followed, up to the beginning of the twentieth century. However, the last great treatise on the theme is that of Frézier (1737-39), whose intent was to operate an overall systematization of the discipline, already clear from the title of the work. The 
discipline of stereotomy reached its theoretical peak in 1798 with the publication of Géométrie descriptive by Gaspard Monge, in which mathematical stereotomy becomes a partial sector of descriptive geometry, changing its nature from a simple "art" to the "science" of cutting solids (Fallacara 2007: 57). While the discipline of stereotomy started with the definitive scientific consecration, from the second half of the eighteenth century we witness the progressive disappearance of architecture built with stereotomic techniques (Fallacara 2007: 56). In this period stereotomy began to be taught for the training of engineers and architects. According to our research (Fallacara 2009: 553-554) the Ecole du Génie de Mézières was one of the first military engineering schools of Europe in which stereotomy was treated as an academic subject from its foundation in 1748. The Ecole des Beaux-Arts and the Ecole Polytechnique, representative of the fields of architecture and engineering respectively, also share the common teaching of stereotomy from the beginning of the nineteenth century, although they have different, specific teaching programs. Stereotomy was considered one of the most suitable subjects for encouraging students to "design the space" and for stimulating their imagination. In those years stereotomy became the fundamental subject in the first years of education for both architects and engineers. Concluding, it is possible to state that "Stereotomy 1.0" comprises the first development of the discipline, in which the design and fabrication processes were exclusively manual.

\section{Towards Stereotomy 2.0: The Birth of Digital Stereotomy}

The interest in stereotomy re-emerged, within the field of construction history, in the early 1990s. This new favourable cultural climate allowed the rediscovery of the discipline not only for its historical importance, but also for its design potential. It is known that stereotomic architecture has always been characterised by considerable architectural and geometric complexity and thanks to the diffusion of the threedimensional modelling and digital manufacturing tools, the conditions to design and create new stereotomic architectures have been created.

The first contribution in which the term "digital stereotomy" appears is the doctoral thesis of Fallacara (2003), which contains a taxonomic classification of the stereotomic elements taken from the most important stereotomy treatises, grouped into classes and types of the traditional architectural morphological and constructive themes, followed by a large work of three-dimensional re-modelling (Fallacara 2003). Fallacara provides another important theoretical contribution defining the three invariants of stereotomy (Fallacara 2003: 43-44): the prefigurative invariant, which is the subdivision capacity in appropriate sections of a vaulted system; the technical/geometric invariant, which is the capacity of geometric, punctual definition of an architectural system and of ashlars and its realization (projective and cutting technique); the static invariant, which is the capacity of providing static balance of the architectural system of drystone joint (graphic and mechanic static of rigid structures).

This contribution officially opened the way to contemporary stereotomic design experiments (Fallacara 2007, 2012) and is the basis of the research contained in this 
article. In the same period, the Department of Architecture of the Politecnico di Bari, under the guidance of Prof. Claudio D'Amato, developed a research project aimed at studying the flat vault of Joseph Abeille from a historical, design and engineering point of view (De Nichilo 2003; Uva 2003).

As is well known, the patent for this vault was published in 1699 in Machines et inventions approuvées par l'Académie Royale des Sciences. The patent is subsequently rediscovered thanks to the studies of several historians of architecture and construction, such as de Mantelos (2001: 166) and Rabasa Díaz (1998). They bring to light the theme of the voute plate, or flat vault, which is the rare constructive application of the aforementioned patent developed by the French engineer. The idea of Claudio D'Amato and his Department was to start from the study of history, deriving useful principles for contemporary design (D'Amato Guerrieri and Fallacara 2005). From these experiences would emerge research on topological digital stereotomy presented by Fallacara at the Second International Congress Construction History in 2006 and, during the same year, with Claudio D'Amato at the 10th International Architecture Exhibition at the 2006 Venice Biennale of "Architecture, Cities, and Society" (Fig. 2) in the exhibition "Città di Pietra" ("Cities of Stone"). For that occasion two experimental prototypes were designed and built: the Abeille Portal and the Alexandros Obelisk. Of the two, the Abeille portal is designed parametrically, through the topological deformation of the voûte plate (Fig. 3). In 2006, Joël Sakarovitch published the results of an important workshop held at the Grands Ateliers de l'Isle d'Abeau (GAIA), inaugurated in 2002 (Sakarovitch 2006). Among the topics of the workshop were the concerns with the manufacturing, construction and loading tests of a series of Abeille flat vaults made of local limestone.

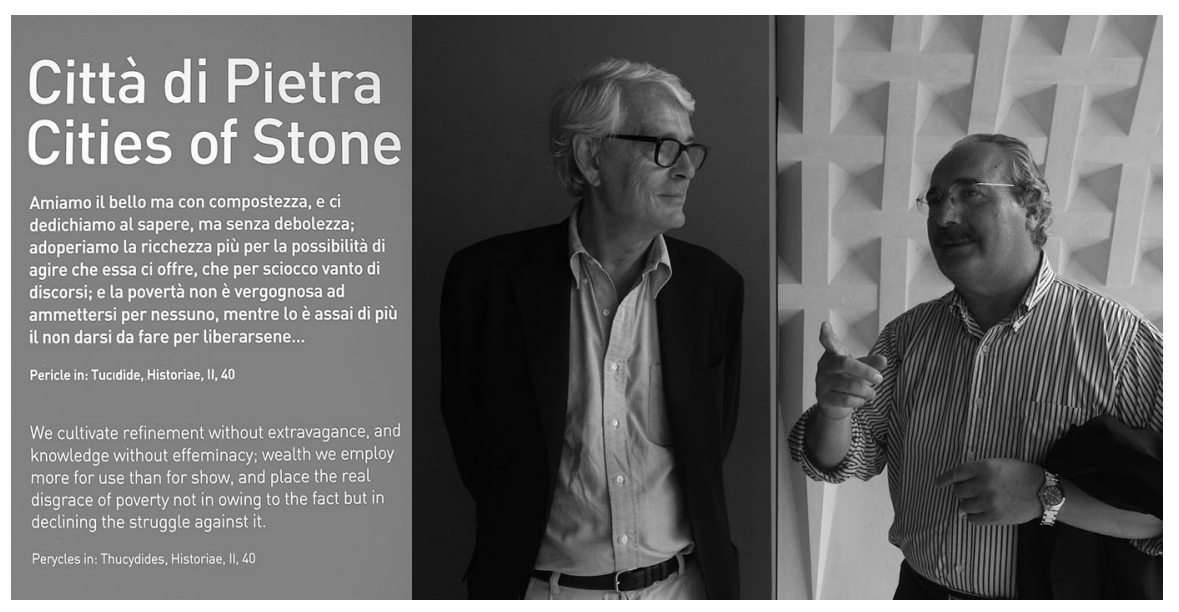

Fig. 2 Claudio D'Amato Guerrieri (right) with Antonio Monestiroli (left) during the opening of the exhibition "Città di Pietra" at the 10th Venice Architecture Biennale. D'Amato is the founder of the Department of Architecture of the Politecnico di Bari and the originator of the research on the use of stereotomic knowledge applied to architectural design. In this picture, D'Amato indicates the manifesto of the exhibition held at Biennale. Photo: Giuseppe Fallacara 


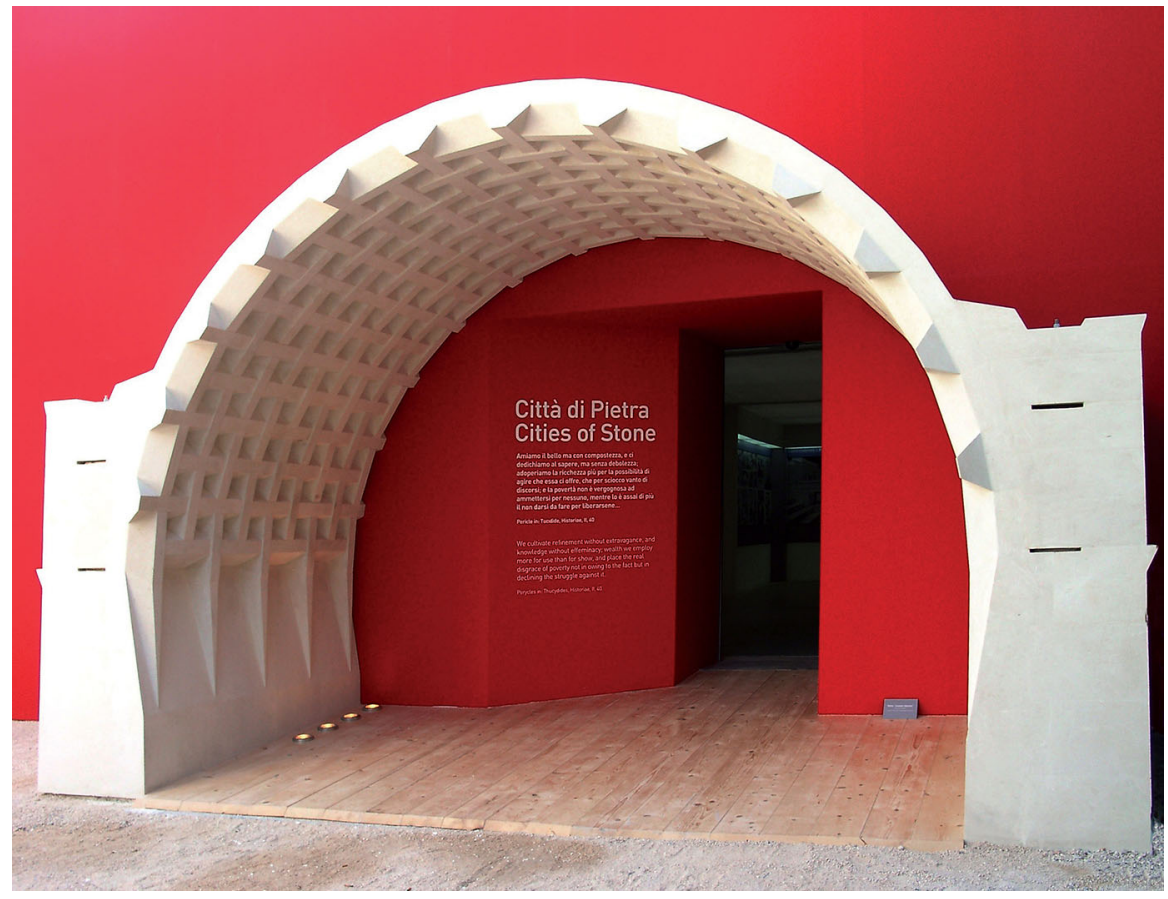

Fig. 3 Designed by Claudio D'Amato and Giuseppe Fallacara, Portale Abeille was the opening gate of the exhibition "Città di Pietra" at the 10th Venice Architecture Biennale. Photo: Giuseppe Fallacara

The patents of Joseph Abeille and Sébastien Truchet are the forerunners of the modern concept of "topological interlocking blocks" (TIB). The TIB concept was introduced in 2001 in the field of materials science in Dyskin et al. (2001) referring to the interlocking aggregative mechanism of a group of identical tetrahedra. According to Estrin (2014), the group continued to work on the subject totally unaware of the previous patents of Abeille and Truchet, subsequently providing other important contributions (Dyskin et al. 2003, 2005; Estrin et al. 2011), which would soon arouse the interest of many other members of the scientific community.

In 2012 Oliver Tessmann resumed the studies of the Dyskin and Estrin group, applying them to architecture with the paper "Topological Interlocking Assemblies". Tessmann re-proposes the Australian group's research in the field of parametric design and digital fabrication (Tessmann 2012; Tessmann and Becker 2013; Tessmann 2013). The Bartlett School of Architecture in the United States provides the workshop "Nexorade and reciprocal structures", in which the topic of the manufacturing of topological interlocking reciprocal blocks from the point of view of robotic manufacturing is explored, using polystyrene blocks cut by means of a robotic arm and hot wire (Schwartz and Mondardini 2014: 199-209).

These experiences are flanked by those carried out at MIT by Prof. John Ochsendorf and the Masonry Group. Among the various research experiences carried out by the group, a fundamental contribution is provided by Philippe Block who, with his doctoral thesis (2009), develops the "Trust Network Analysis" 
(TNA), an operating method based on static graphics, useful both for verifying the static behaviour of existing masonry structures and for the design of new vaulted structures through form-finding operations.

Block later left MIT to found the Block Research Group, at the ETH in Zurich. Since its establishment, the group has specialised in the computational structural design of "discrete shells" (in bricks and stone). In this direction a notable contribution has been provided recently by the doctoral thesis of Rippmann (2016) and Rippmann and Block (2018), which systemised the computational procedures for the form finding and tessellation of discrete funicular shells whose geometrical definition is based on the use of TNA. The search for the whole group takes the form of a large number of scientific publications, the development of plug-in for formfinding "Rhino Vault" and the exhibition "Beyond Bending" at the 15th Biennale in the 2016 Venice Architecture, organised together with the ETH Zürich, Ochsendorf, DeJong \& Block (ODB) and Escobedo Group (Block et al. 2017). This exhibition presented several prototypes, including the Armadillo Vault, a vaulted stone structure.

Other significant contributions are offered by Brandon Clifford who, in his robotic fabrication course at MIT (Clifford 2014), has developed a series of interesting theoretical experiments and reflections on the relationship between volumetric architecture, spring-particle form-finding and digital fabrication (Clifford 2013). The research of Clifford and his studio partner, Wes McGee, consists of a series of experimental prototypes, among which the most significant is undoubtedly La Voûte de LeFevre, using plywood voussoirs manufactured with CNC machines (Clifford and McGee 2014).

The project by Clifford and McGee is not alone in its use of materials other than stone. Although the present discussion focuses more on this material, it is important to provide an overview of stereotomic experiments that also use other materials, since in the scientific literature today the term "stereotomy" is used in a broader sense: it has begun distance itself from its traditional association with stone architecture, approaching instead the literal definition of "science of cutting solids", without any reference to a specific material. In fact, the stereotomic experimentations now includes materials with characteristics in some cases very different from stone, such as cork (Merritt and Varela 2014), polystyrene (McGee et al. 2013), plastics (Diles 2018), autoclaved aerated concrete (Clifford et al. 2016a, b), and other cast materials (Varela and Sousa 2018).

\section{Stereotomy 2.0: The Reasons for Rebirth}

The rebirth of stereotomy (in the updated version 2.0) leads us to reflect on the maturation of the various research experiences so far outlined towards the definition of mainstream best practice. In this process towards a mainstream application of Stereotomy 2.0, it is not possible to ignore the didactic value of the discipline. The didactic value resides in two aspects: on the one hand, the ability to highlight the importance of the rediscovery of the historical heritage of stone buildings (and particularly those stereotomic) in order to show the highest speculative peaks 
reached by the art of building; on the other hand, to show the intrinsic ability of the discipline to favour a strongly holistic approach to architectural design, in a design process in which continuous reflection on a comprehensive concept of the project is encouraged. The teaching of Stereotomy 2.0 can lead to faster and more natural evolution of technological literacy in the schools of architecture. Precisely because of its holistic approach, Stereotomy 2.0 makes it possible to better understand the use of technological tools for designing and manufacturing (digital or robotic), without ever losing sight of the ultimate purpose for which these tools must be used: the improvement of the quality of architecture, in various aesthetic, material and constructive meanings. In fact, classic stereotomy has always been accompanied by the use of the most advanced design and manufacturing techniques available. In this sense it is sufficient to think about the development and evolution of the geometric techniques employed by stereotomy between 1500 and 1900: from trait géométrique to projective geometry, to the descriptive geometry. However, while in the past the techniques of stereotomy were jealously guarded by the French stonemason guilds, the technological knowledge available today can take advantage of the accessibility and speed with which information is disseminated and shared in the global world permeated by information technology: from the Masonic secrets of French masons to contemporary open access and open source.

The transition to Stereotomy 2.0 also leads to a reflection aimed at developing a critical comparison in order to outline the possible frontiers for the future development of the discipline, the possibility of relaunching the research of recent years in a global and international context and, finally, to investigate and show the unexpressed potential of the discipline. In fact, it is important to underline the fact that Stereotomy 2.0 is part of a much wider digital renewal movement: the historical assumption underlying this renewal is to be found in the dissemination of parametric-computational design tools, digital manufacturing (CNC machines) and robotic tools. As is well known, between the 1990s and the 2000s, the widespread use of computers in architecture not only changed the way buildings are designed, but also helped to change the way they are built. Hence the need to develop digital fabrication, defined as the manufacturing process in which the physical model is fabricated by computer-controlled machines directly from the digital model. Digital fabrication reduces the distance between the digital model and the real object. However, this distance can be reduced only if the designer is aware of the tools he employs when the design is under development. This is especially true for Stereotomy 2.0 because of its strongly holistic approach. However, it is important to point out that here we reference not only the correct use of the tools, but also the correct development of the project, in which the parts and the whole are shaped in such a way as to collaborate inextricably and synergistically. Moreover, as an experimental discipline, Stereotomy 2.0 cannot be separated from constructive experimentation, not only through the creation of demonstrative prototypes but also, hopefully, from true architecture. 


\section{An Unfinished Manifesto for Stereotomy 2.0}

Why do we write an "unfinished" manifesto? Inspired by Mau's (1998) incomplete manifesto, we propose our reflections in order to start and stimulate an academic and professional debate on the subject, intended as an important topic for the future of contemporary architecture. The following ten points will outline different aspects of the reborn discipline, completely founded on digital tools for design, fabrication and construction.

1. The rebirth is based on the "Stereotomic Paradox": lightness versus heaviness Stereotomy materialises by means of heaviness and compression of its materials, but is still able to be paradoxically light, against its own premises. Philibert de l'Orme, the historical identifier of stereotomy as a powerful tool for the design in the hands of the architect, had a deep and constant longing for lightness his works, which appear to defy the laws of gravity, turning the stone material into an elastic one, both in the aesthetical outcome and in the structural response (de l'Orme 1567). In this regard, the celebrated vaults realised in the chapel and hallway of the Château d'Anet are paradigmatic. The most famous one is the conical vault-trompe of the Cabinet du Roy: " $e$ me sembla estere fort bon d'y faire une voute surpendue en l'air". The paradox is a constant in the logic of the stereotomic design, thus aiming at a formal lightness starting from the opposite material condition (Etlin 2012). The paradox of stereotomy was very well described by Charles Perrault: stereotomy is the art "... de se servir de la pesanteur de la pierre contre ellemême et de la faire souvenir en l'air par le même poids qui fait tomber..." (quoted in Pérouse de Montclos 2001: 85). This definition can be summarised as the art of using the weight of the stone to enhance the lightness of the forms, thus claiming the combination weight versus lightness in the same architectural element. In building practice this can be seen when a vault system is built. The vault, in order to maintain its balance, has to be characterised by a considerable weight of the stone blocks, going into compression to ensure the balance of the whole arched system. The lesson of this assumption is related to the desire to create a light vaulted space, resulting in a paradox in respect with its enormous and intrinsic weight.

2. It is based on the Michelangelo's poeticism of "taking away to build" Michelangelo considered sculpture as the art of taking away in order to reveal all that was already contained in the matter from the origin. This ability is obviously initiatory, in the sense that in order to be able to foresee in the raw block the finished voussoir, it requires knowledge, competence and the ability to learn. Symbolically, the raw block represents the initial phase of learning and the finished voussoir is the achievement of disciplinary knowledge. Materially, the action of removing to achieve the desired final form, if applied to a raw material, theoretically including but not limited to stone, imposes an assumption of responsibility related to the limitation of the waste of the material produced (see point 3 ). 
3. It aims to develop a geometrical-ethic design: near-zero material waste and reuse of not renewable materials, from subtractive to additive manufacturing Stereotomy 2.0 requires a reflection on the importance of developing design ethics in which the geometry of the designed elements produce as little waste as possible. The new discipline emphasises the importance of basing project speculations on this fundamental intent. The ideal condition would be to design the architectural ensemble in such a way that its constituent parts can be obtained with the least possible waste of non-renewable material, a sort of optimization and "volumetric nesting" between the raw block and the final voussoir. With this concept it would be desirable to design with the aid of specific algorithms able to calculate and predict the best subdivision (tessellation) of a vaulted space according to the best method of cutting the voussoirs-components, in order to manufacture the final product with the lowest possible quantity of stone scraps. In any case, considering the impossibility of not making waste in subtractive transformation processes, the designer must question how to reuse the scraps themselves for the realization of new projects. The waste from the subtractive production processes can be reused according to the technologies of additive manufacturing. In this sense, the use of such technologies must be privileged to achieve a discrete construction, made up of parts. For the "additive" stereotomy, the concept of physically cutting the matter disappears, but not the conceptual one related to the tessellation of the voussoirs. The latter remains and is sublimated in the digital environment, where the project is substantiated and the material is "cut" starting from the indefinite digital mass.

4. It is made of various materials: natural, artificial, hybrid, volumetric, lightweight, heavy

There is the possibility of using not only natural materials, but also artificial or hybrid ones with Stereotomy 2.0. In order to broaden the expressive possibilities of the discipline and overcome the limitations imposed by the individual materials, the use of composite material born from the union of materials with different and complementary characteristics is encouraged. Moreover, with Stereotomy 2.0 the specific use of heavy materials is not mandatory, allowing the use of light-weight materials. Thus the condition for determining whether an architecture is stereotomic is the use of discrete and volumetric components.

5. It is designed and fabricated by digital and computational tools

Stereotomy 2.0 is closely related to the use of digital design and manufacturing tools. With the genesis of the project always being digital, so is its materialization. In this sense, any innovation in the field of digital technologies becomes a tool for new design speculations, without any limitation other than that deriving from conceptual rigor and the beauty of the designed architecture. As in the past, even Stereotomy 2.0 evolves with the progress of techniques and technologies and the speculative thinking typical of its era. It is variable and evolutionary, in step with the times, interpreting new meanings and incorporating new aesthetic manifestations. 
6. It is designed according to the intrinsic limits of the fabrication method used Whether using subtractive or additive manufacturing processes, Stereotomy 2.0 takes into account the technological limits of the manufacturing tools used and must inform the project in such a way that it is consciously harmonised within the limits of the instruments used. Therefore, the designer must know and reflect on the manufacturing tools he/she uses, so that the tools themselves can be an inspiration for future design explorations. Its design product is not limited as it is dominated by technology (it cannot be a "by-product" of technology); on the contrary, the design for Stereotomy 2.0 is a constant investigation (pushed to the limit of a given technology) of the intrinsic limits of a given technology.

7. It is designed with attention to architectural details

The etymology of the word "detail" comes from the French term détail, formed of de and tailler, meaning cutting or breaking. Thus, de-tailler explicitly refers to detail as an operation aimed at cutting stones (in French, taille de pierre). By extension, stereotomy refers to the science of cutting solids. Therefore Stereotomy 2.0 aims to design and fabricate the architectural detail with a specific level of attention. In particular, development of architectural details is considered important for the new discipline not only as an expression of the various parts with respect to the whole (relationship between the parts and the global shape), but also as an expression of important architectural attributes from the functional point of view, and as vectors of aesthetic characterizations in term of sensoriality and emotionality.

8. It aims to reveal three levels of beauty

Stereotomy 2.0 has among its primary objectives that of pursuing beauty in architecture. The first level of beauty to which we refer is that of the material used, an unrepeatable "pattern" created by nature or artifice, and its changing appearance based on its natural aging over time. The second level of beauty is related to the overall architectural form, which can either obvious obey the laws of gravity, or appear to challenge it wisely and conscientiously. Finally, the third level of beauty is that of the local geometry of its constituent elements, the voussoirs, in order to reveal the ordered charm of the tessellation used to achieve the best contact between the parts without compromising the beauty of the whole.

9. It is a discipline related to architectural design and construction

Stereotomy 2.0, although hybridised with other related disciplines, is mainly an architectural discipline, and is particularly related to architectural design. Its objective is therefore to contribute to the improvement of the processes and outcomes of contemporary architectural design and construction. Stereotomy 2.0 emphasises a conscious use of digital tools and technologies, the use of resources and the quality of the construction, which is expressed in a perfect connection between the parts and a synergistic relationship between the parts and the whole. This is possible if the quality of the project and the realization become essential parameters to be considered and respected. With Stereotomy 2.0 we somehow go beyond the orthodox idea of stereotomy as a discipline 
useful to design architectural forms subject to compression-only stresses; rather, it aims to emphasise the general complexity of the form in its different meanings, both theoretical and constructive. In any case, the idea of the structural optimization or the form finding of a stereotomic design has never existed in the historical literature of the discipline, since these concepts have developed successively and in more recent times: from an application related to thin, continuous and multi-tensional shells, to the compressed discrete "shells". Form-finding and structural optimization can both be useful tools for the optimal definition of architectural form, but they cannot be aimed at reducing design to an exclusively algorithmic and mechanistic logic. For Stereotomy 2.0 it is more important to demonstrate that one is able to realise, with conceptual and constructive perfection, a "complex architecture" (in the dual theoretical and formal meaning), rather than demonstrating that the form was chosen for its "perfect" structural behaviour under compression-only stresses. From these considerations it is possible to associate a new critical category to a part of contemporary architecture, which we can define "Stereotomic Design". This new conceptual category of architecture therefore brings about the possibility to analyze the relationship between the part and the whole; the conceptual, geometric and constructive perfection; the quality of the materials and their relationship with the wear and tear of time; the extreme coherence or, in contrast, the apparent paradox with which they are used.

10. It is designed by the Novus Architetto Adaucto

Stereotomy 2.0 is a design-to-production process. The direct relationship between designers and the final product is established thanks to robotic fabrication of stereotomic elements. The contemporary designer is a novus architetto adaucto or an "expanded designer" in the sense that he possesses new (robotic) arms which allow him to cut and shape the materials according to his direct requirements (almost) without any external mediation. In this perspective, the famous illustration Habit de l'Architecte made by Nicolas II de Larmessin ${ }^{1}$ in 1695 changes both because of the new tools at its disposal and of the new forms that he is able to produce (Fig. 4).

The direct control of the fabrication of the work by the designer is the first step to redefine a new profession, paradoxically similar to the architect-master of the past. In this new scenario, the new architect of the future is the author and creator of his own work, or at least the one who ensures for the final work the most suitable correspondence with the original idea of the project without mediation and/or constructive interpretations by others. The new designer takes on new critical skills, goes back to the actual construction and assumes new ethical and civil responsibilities of his job. Thanks to the development and dissemination of digital knowledge related to manufacturing (the fabrication laboratory, or FabLab), this process of redefining the role of the designer can occur at any scale, from

\footnotetext{
${ }^{1}$ Nicolas II de Larmessin (or L' Armessin), from the series of engravings entitled Les Costumes Grotesques: Habits des métiers et professions (Paris, 1695), fol. 69.
} 


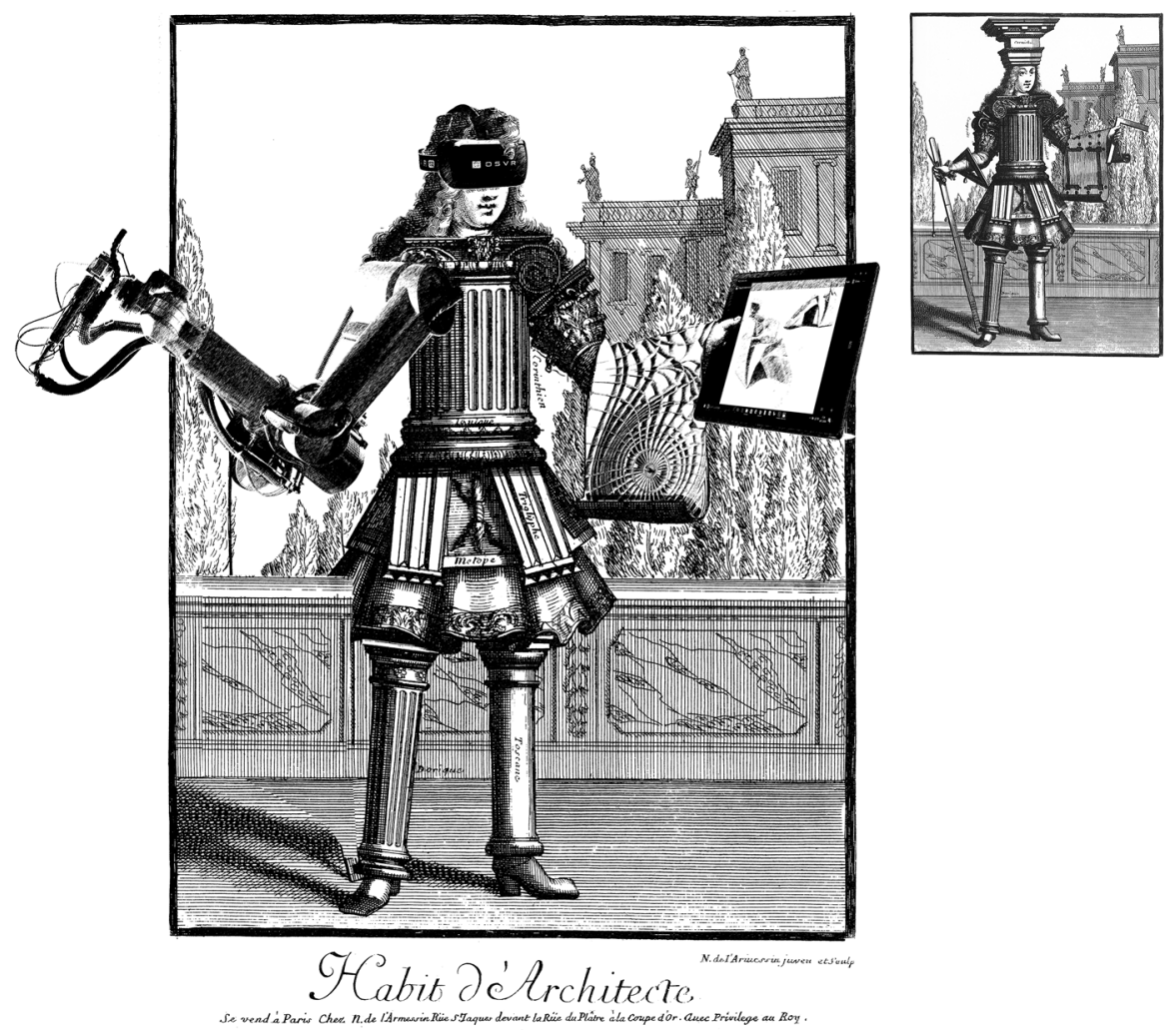

Fig. 4 Reinterpretation of de Larmessin's Habit de l'Architecte (1695). Image: Giuseppe Fallacara

architecture to design product, and at any level of business activity, from big industries to small workshops.

\section{Stereotomy 2.0: Exploratory Design and Stone Prototypes}

Historically, stereotomy is strictly related to stone, and for this reason our exploratory design work is related to this material. Stone is considered to represent an "old" material, that is, it strongly connects to the forms of the past and tradition. In addition, stone is considered difficult to use both for product design and contemporary architecture compared to the "modern" materials. However, the truth is that for a designer there are no ancient or modern materials; rather, it is the way the material is worked, shaped and transformed that makes it new and innovative rather than old and outdated. It is important to note here that most of the formal innovations and applications, especially for stone, derive from the knowledge and reflection on the architecture of the past. The study of ancient monuments makes it possible to understand the building expertise and to attempt to go further by 
following the relevant phrase of Bernard of Chartres, who said that one could look further by "standing on the shoulders of giants".

Unfortunately, nowadays, many people considers that it is quite "illogical" to think about recovering the techniques and the traditional use of stone in architecture and in contemporary design for several reasons. First of all, today there is a lack of knowledge and culture about stone as a material; in the past, this knowledge was acquired primarily at workshops, schools and in the general culture of a community, and this made it possible to generate the great heritage of humanity which includes cities and historic monuments. Second, legislation does not foster the use of stone as a building material. The rules and the current building regulations make evident both of the limits of the material and the enormous difficulties of adapting the technique to meet current standards. This second aspect derives directly from the first point, that there is inadequate knowledge of the material and its use in the history of building. Finally, in contrast to contemporary concepts of "temporary", "provisional" and "rapidly-changing" styles, the stone building remains standing throughout time. It witnesses itself and its author defying time and leaving a mark in history: this is one of the absolute values of our attention towards stone. The projects we shall now illustrate describe an effort to demonstrate new applications, features, shapes, unexpected and unexpressed potential of stereotomy for contemporary architecture. All of them aim to show the search for a balance between geometric complexity and the limitations derived from the static and mechanical resistance of the elements. Searching for the limit of the potential applications of a material is useful for broadening knowledge and expanding the frontiers of its achievements and uses.

1. Bin Jassim Dome

The Bin Jassim Dome is a geodesic dome in stone constructed of reciprocal Abeille voussoirs, designed by Giuseppe Fallacara, in collaboration with Maurizio Brocato (engineering), Luc Tamborero (assembly) and the company S.N.B.R. (fabrication) (Fig. 5). The design of the dome involved various fields such as tessellation, Platonic volumes, stereotomy and nexorades. The main idea came from the three-dimensional models created using topological modelling tools by Giuseppe Fallacara (Etlin et al. 2008: 75-79). The final model of the vault was engineered using software such as Mathematica. Compared to a traditional dome, the Bin Jassim Dome presents some remarkable advantages in terms of weight of the structure: 6.75 tons instead of 11.8 tons. The reciprocal configuration of the voussoirs permits an innovative structure in which structural strength and aesthetic aspects are embedded together.

2. HyparGate

HyparGate (Fig. 6) is the first discrete hyperbolic paraboloid made of stone, designed by Giuseppe Fallacara and defined parametrically by Maurizio Barberio. The HyparGate covers a free area of 22 square meters thanks to the cantilever morphology of the shell. The hypar is a well-known ruled surface, which has been used in recent decades for many structural applications related to reinforced concrete shells. The full-scale construction is located in France 


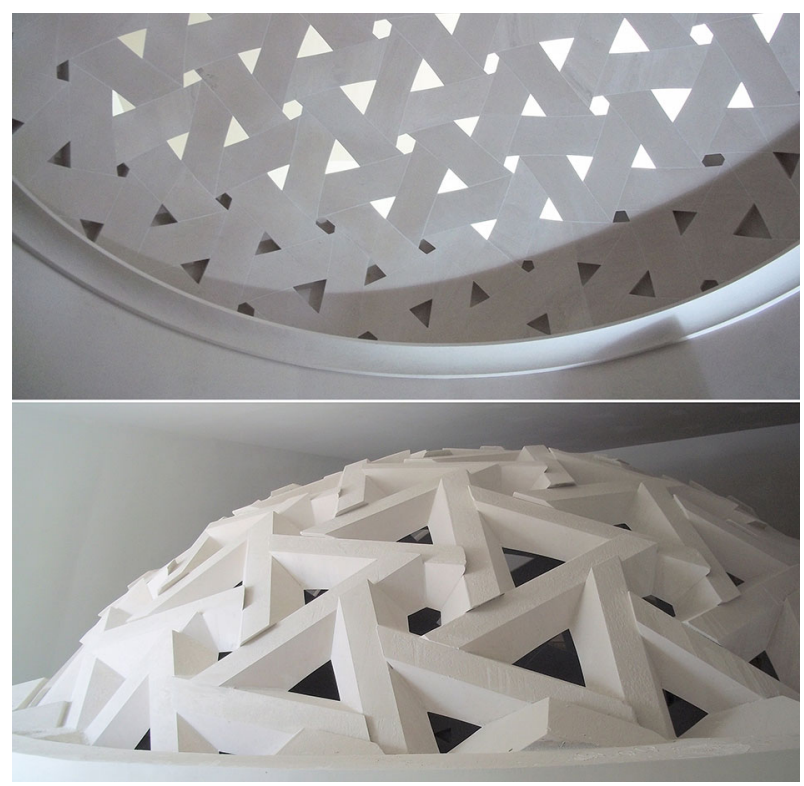

Fig. 5 The Bin Jassim Dome, 2012, intrados and extrados. Photo: Giuseppe Fallacara

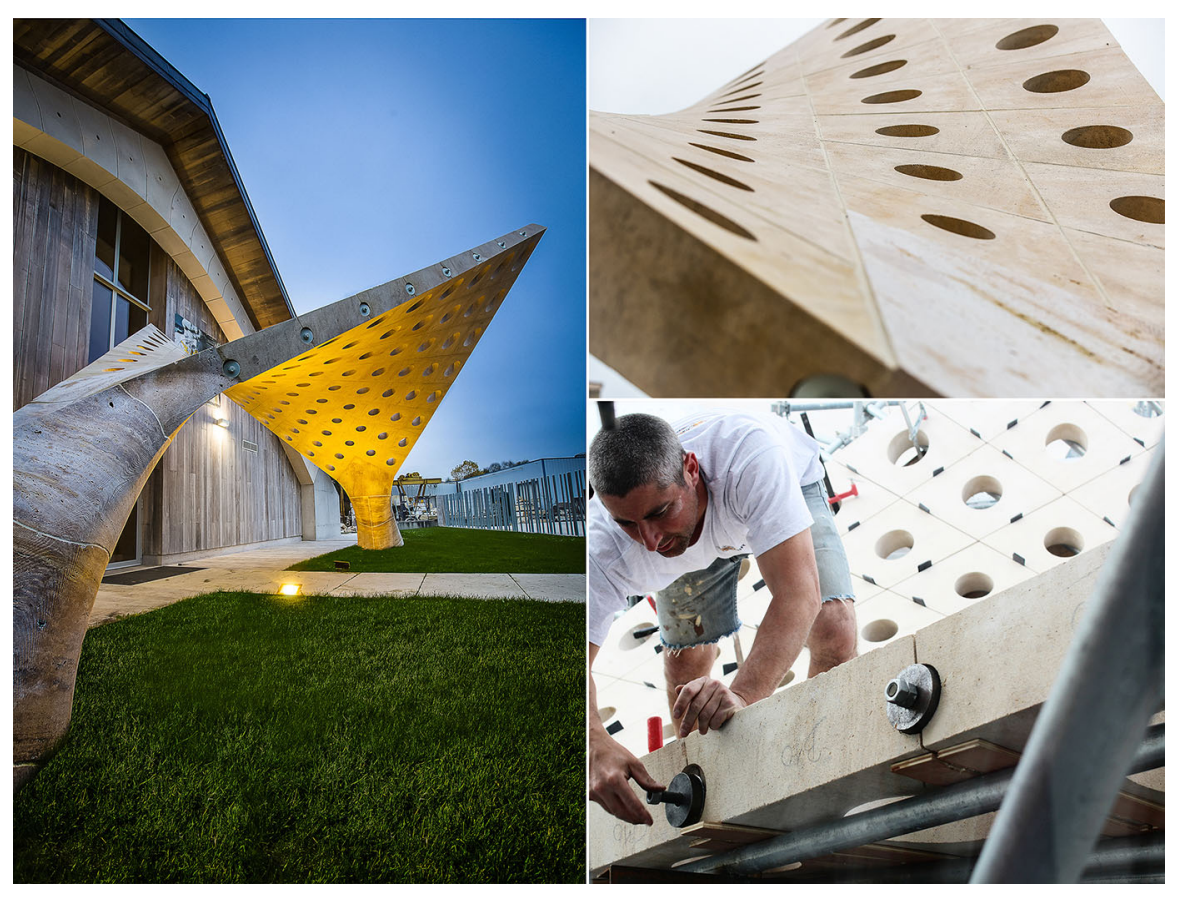

Fig. 6 The Hypar Gate, 2016. Photo: GaZ Blanco (finished) and Micaela Colella (construction) 
and represents the entrance portal of the headquarters of the French company S.N.B.R. The main idea is to replace reinforced concrete with pre-stressed stone through a post-tensioning technique, in order to reduce the use of artificial materials in architecture, when possible. Prestressing simply means that the steel reinforcement is stressed (pulled or tensioned) before the stone must support the live loads.

3. HyparWall

HyparWall is a modular perforated stone wall that can be used for either exterior or interior applications, ensuring multiple configurations: along straight, curved or cylindrical courses thanks just to two basic ashlars which are easy to produce and assemble. These voussoirs are made from recomposed stone using scraps of the stone native to Lecce generated during other processing stages. The cemented ashlars have a "saddle" shape (hyperbolic paraboloid) that exploits the properties of grooved surfaces in order to optimise mass production using the mould and counter-mould technique. It is also possible to produce natural stone ashlars by cutting the material with diamond wire mounted on a robot arm. The two typical hypar voussoirs are mirror images of each other. The wall was designed by Giuseppe Fallacara and was presented at Marmomac Verona, Italy, in 2016 and 2017 (Fig. 7).

4. HyparVault

HyparVault (Fig. 8) is a barrel vault consisting of perforated stone blocks cut

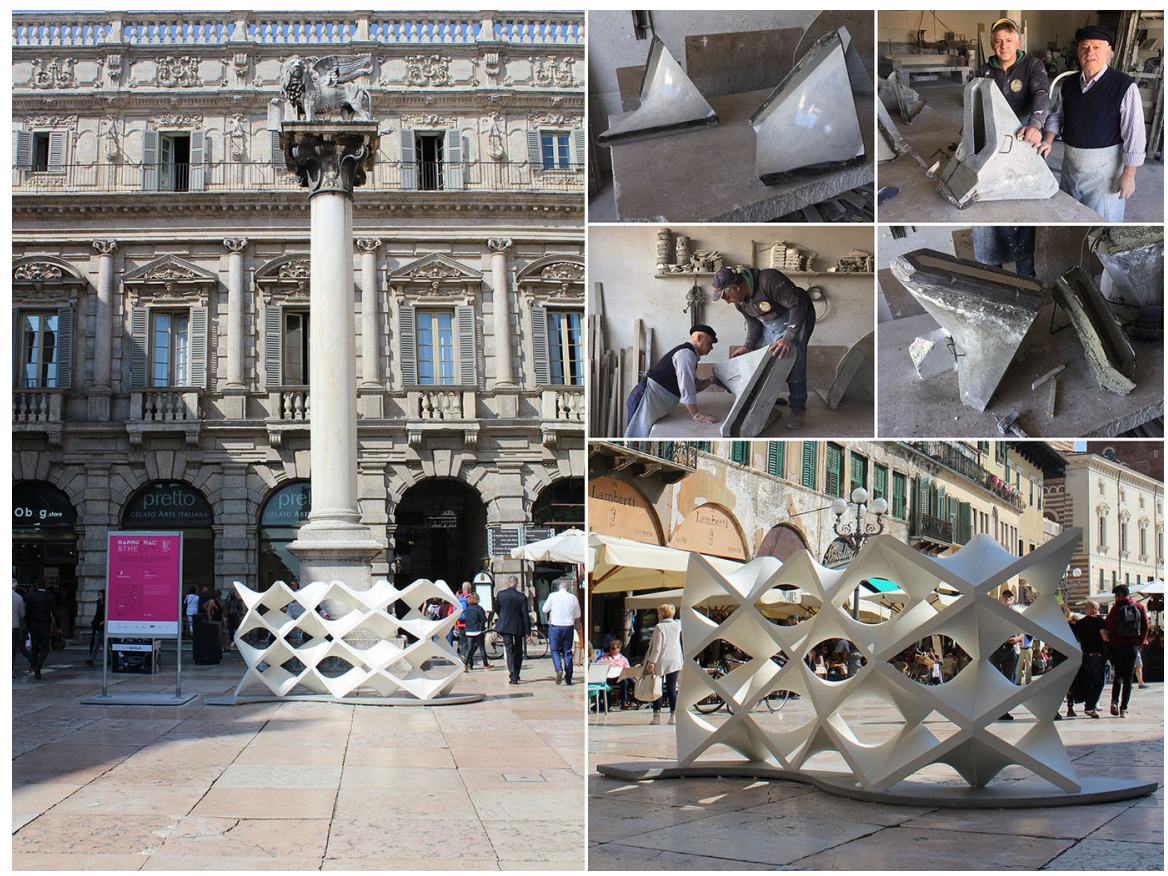

Fig. 7 The HyparWall exhibited in Piazza Erbe, Verona, 2017. Photo: Maurizio Barberio and Giuseppe Fallacara 


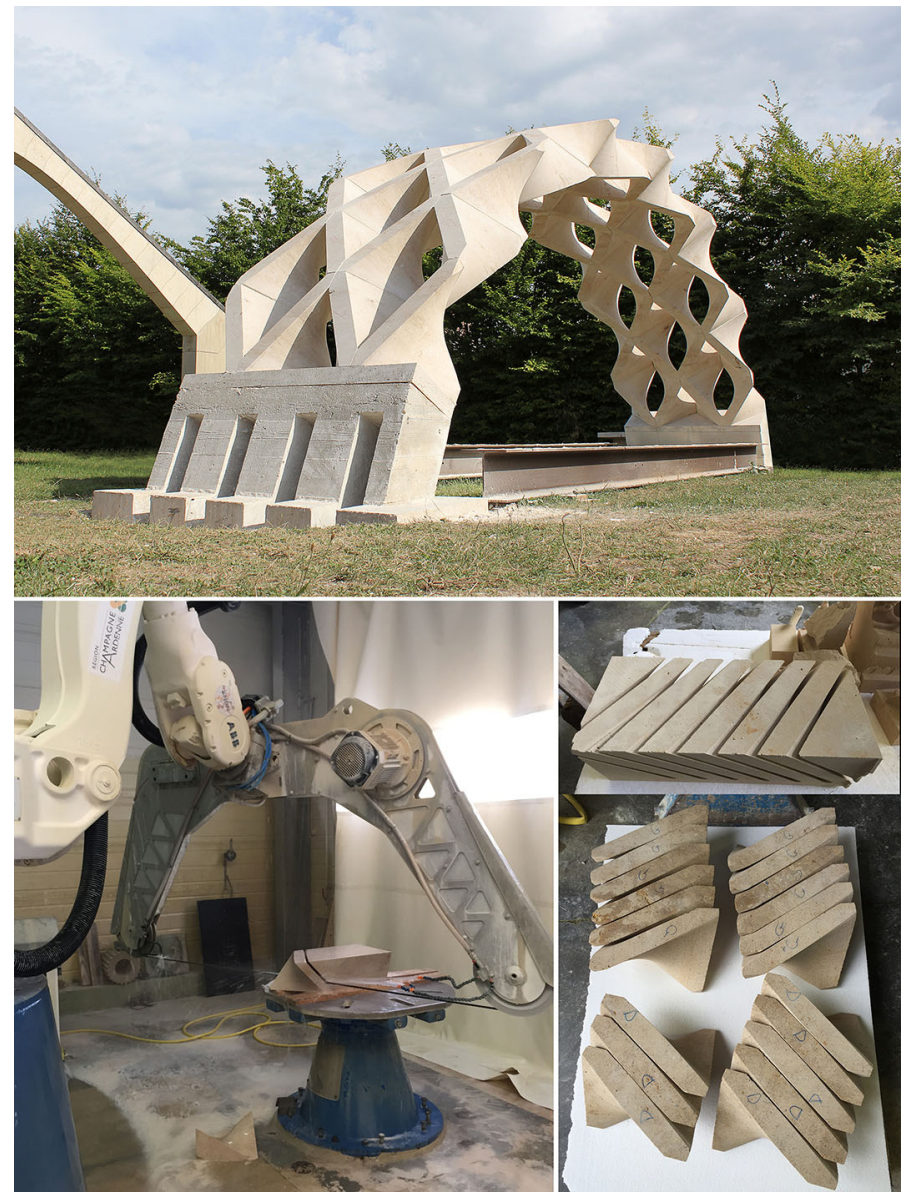

Fig. 8 The HyparVault, 2017. Photo: Maurizio Barberio

with diamond wire, designed by Giuseppe Fallacara and defined parametrically by Maurizio Barberio. It is a prestressed vault with post-tensioned steel cables. The vaulted structure is composed of only two types of voussoirs with the same logic previously presented concerning the HyparWall system. In this specific case, the blocks with hyperbolic paraboloid geometry have trapezoidal forms and are axially perforated to allow the passage of the stainless steel cables inside. The prestressing of the structure occurs due to post-tensioning of steel cables which are fixed to the base of the barrel vault. The cutting of the material with diamond wire mounted on a robotic arm allowed for minimal waste of the stone material. The HyparVault is part of a broader research project called Architectural Hypar System, currently under development in collaboration with LabCity Architecture from Università di Palermo (Prof. Renzo Lecardane) and the French company S.N.B.R. 
5. Flux Vault

Flux is a vaulted pavilion in stone designed by Giuseppe Fallacara and Maurizio Barberio in collaboration with the French company S.N.B.R. The pavilion represents the design of the display booth of the same company and was designed for Rocalia, the fair dedicated to natural stone held in Lyon in December 2017 (Fig. 9). Flux covers an area of $36 \mathrm{~m}^{2}(4.5 \times 8 \mathrm{~m})$ and has a maximum height of about 3.20 meters. The shape of the pavilion derives from a base surface formed by a network of exclusively inverted catenary curves, in order to make the vault predominantly subject to compressive stresses. The structure was designed to be mounted very quickly ( 1 working day) with the help of very limited support structures in order to avoid the construction of a true centring. Each block was designed to weigh less than $500 \mathrm{~kg}$, so as to facilitate quick assembly. For this reason, on the contact faces of each voussoir there is a metal fixing system, glued to the stone voussoirs by epoxy resin. A

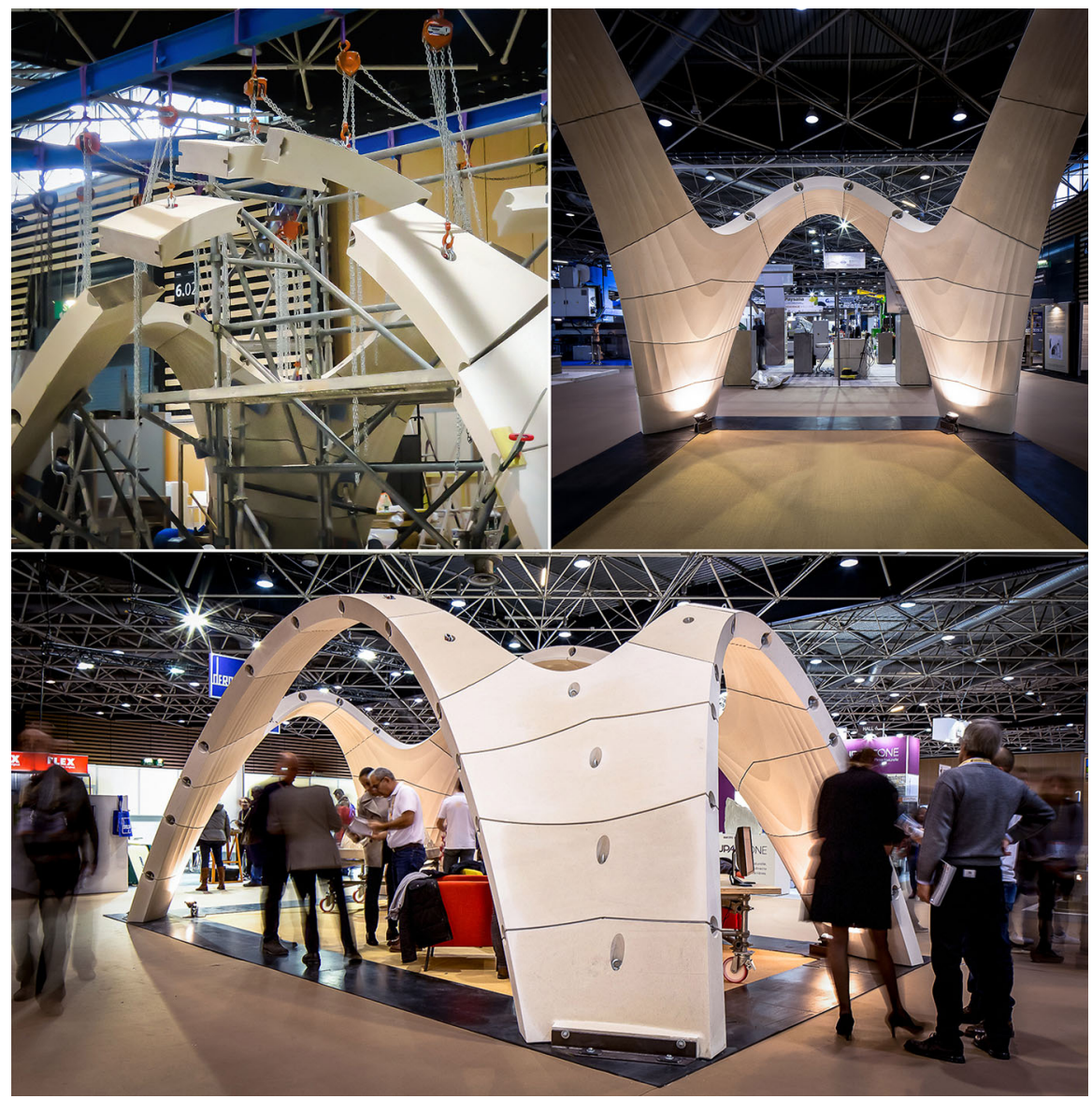

Fig. 9 Flux, exhibited at Rocalia fair, Lyon, 2017. Photo: GaZ Blanco (finished) and S.N.B.R. (construction) 
bolted fastening system placed on the plates at the outer edges of each concave stone voussoir serves to join the segments between them. The manufacturing process of the first voussoirs demonstrated the perfect correspondence between the digital model and real production. The manufacture of the voussoirs, due to the complexity of their morphology, requires the exclusive use of a robotic arm. The sculptural relief of the intrados visualises the flow of internal forces to the structure, drawing its path, without discontinuity from the key to the ground.

6. Osteomorphic Catenary Arch

The Osteomorphic Catenary Arch (Fig. 10) is an arch whose curve evokes a long chain held by both ends and left hanging. It looks like a parabola, but has a different geometry. The catenary arch is also known as a "balanced arch" because its shape allows a uniform load redistribution. Unlike other types of arches, it does not need either buttresses or other supporting elements and abutment. The catenary curve constitutes the base to match the osteomorphic stone blocks, similar to the wave-shaped blocks presented in Estrin et al. (2011). In this case, all the stone blocks undergo a topological deformation so they are geometrically similar but they have dimensional and angular variations. The realization of the individual blocks, of great geometric complexity, is only possible through the use of CNC machines. Each individual block was individually numbered for easy identification during the next assembly step, when the blocks were placed on the ground and assembled in the form of the catenary arch. The construction system also applies in barrelvaulted systems with catenary sections in a conception of mechanically
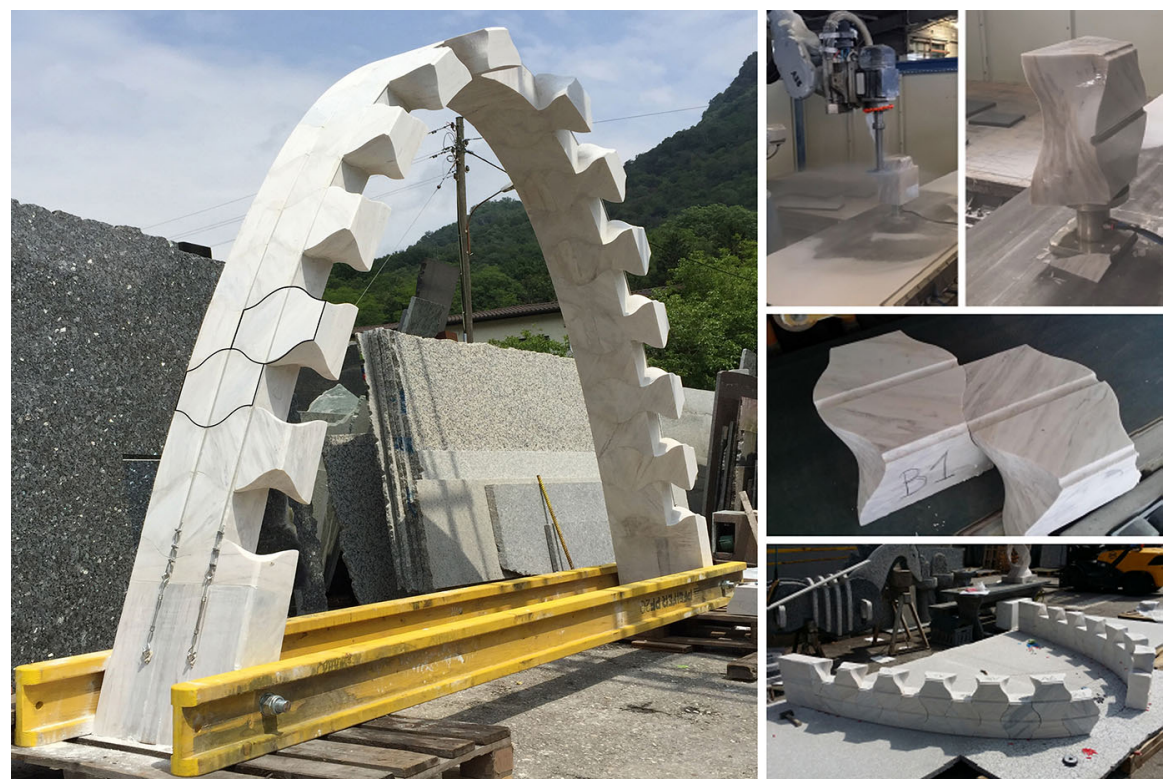

Fig. 10 The Osteomorphic Catenary Arch, 2015. Photo: Giuseppe Fallacara 
mounting. The arch was designed by the Giuseppe Fallacara and fabricated by the Swiss company Generelli SA.

\section{Conclusions}

The "unfinished manifesto" of Stereotomy 2.0 presented here is intended to provide a new starting point for the contemporary speculations that have been developed by many designers in the last 15 years. Further, the experimental prototypes presented are aimed at showing a small part of the potential that Stereotomy 2.0 may express in the future. Stereotomy 2.0 holds great promise for contemporary architectural design and construction. The next 15 years may be considered as a new check point for the evaluation of the results inspired by this contribution. The event "Stereotomy 2.0 and Digital Construction Tools" (Colella 2018) held in New York during April 2018 proposed to the international public the first conceptual and built examples of research projects based on the ideas of this manifesto.

Acknowledgements The overall structure and narrative of this paper are the result of the combined work of the two authors. Section 1, "Introduction", was written by both together; Sect. 2, "The Spiritual Foundation of Stereotomy" was written by G. Fallacara and edited by M. Barberio; Sects. 3 and 4 were written by M. Barberio under the supervision of G. Fallacara; Sects. 5, 6, 7 and 8 were written by both authors. However, regarding Sect. 6, points number 1, 2, 8, 9 and 10 of the manifesto were mainly written by Giuseppe Fallacara; points number 3, 4, 5, 6 and 7 of the manifesto were mainly written by Maurizio Barberio. The authors consider their individual contributions to whole to be equal $(50 \%)$.

\section{References}

Barberio, Maurizio. 2018. Nuove frontiere dell'Architettura in Pietra: progettazione parametricocomputazionale, fabbricazione digitale e costruzione. Ph.D. thesis, Consorzio argonauti: Politecnico di Bari and Università degli Studi Roma Tre.

Block, Philippe. 2009. Trust Network Analysis: exploring three-dimensional equilibrium. Ph.D. thesis, Massachusetts Institute of Technology.

Block, Philippe, Tom Van Mele, Matthias Rippmann and Noelle Paulson. 2017. Beyond Bending: Reimagining Compression Shells. Munich: DETAIL.

Clifford, Brandon, McGee, Wes and James Durham. 2016. Round Room. In: ACADIA Posthuman Frontiers: Data, Designers and Cognitive Machines, Projects Catalog 2016, 190-195. https:// static1.squarespace.com/static/5307a330e4b06dde7ef78d6f/t/58b2f342579fb3b2016d9983/ 1488122696159/2016_190_RoundRoom.pdf. Accessed 10 Jan. 2018.

Clifford, Brandon. 2013. Thicker Funicular: Particle-Spring Systems for Variable-Depth FormResponding Compression-Only Structures. In: Structures and Architecture: New concepts, applications and challenges, ed. Paulo J. Sousa Cruz, 668-675. London: Taylor \& Francis.

Clifford, Brandon. 2014. Volumetric Robotics: MIT Architectural Design Workshop. Boston: Matter Design Press.

Clifford, Brandon and Wes McGee. 2014. La Voûte de LeFevre: a variable-volume compression-only vault. In: Fabricate: Negotiating Design and Making, eds. Fabio Gramazio, Matthias Kohler and Silke Langenber, 146-153. Zürich: gta Verlag.

Clifford, Brandon, McGee, Wes and James Durham. 2016. Round Room. In: ACADIA Posthuman Frontiers: Data, Designers and Cognitive Machines, Projects Catalog 2016, 190-195. https:// static1.squarespace.com/static/5307a330e4b06dde7ef78d6f/t/58b2f342579fb3b2016d9983/148812 2696159/2016_190_RoundRoom.pdf. Accessed 10 Jan. 2018. 
Colella, Micaela. 2018. Stereotomy 2.0 and Digital Construction Tools (Conference Report). Nexus Network Journal 20(2). In press.

Cosmas Indicopleustes. 2010. The Christian Topography of Cosmas, an Egyptian Monk: Translated from the Greek, and Edited with Notes and Introduction by J.W. McCrindle (1897). Rpt. Cambridge: Cambridge University Press.

Curabelle, Jacques 1644. Examen des oeuvres du Sieur Desargues. Paris: Henault.

D’Amato Guerrieri, Claudio and Giuseppe Fallacara. 2005. L'arte della stereotomia. I compagnons du Devoir e le meraviglie della costruzione in pietra/L'art de la stéréotomie. Les Compagnons du Devoir et les merveilles de la construction en pierre. Paris: Librairie du Compagnonagge.

De L'Orme, Philibert. 1567. Le premier tome de l'architecture. Paris: Fédéric Morel.

De Nichilo, Eliana. 2003. Learning from stone traditional vaulted systems for the contemporary project of architecture. In: Proceedings of the First International Congress on Construction History (Instituto Juan de Herrera, Madrid, 20th-24th January 2003), ed. Santiago Huerta, 743-754. Madrid: Instituto Juan de Herrera.

Diles, Justin. 2018. Lightweight Stereotomy with Glass-Fiber Reinforced Plastic. Nexus Network Journal 20(2). https://doi.org/10.1007/s00004-018-0376-X

Dyskin, Arcady V., Estrin, Yuri, Kanel-Belov, Alexei J. and Elena Pasternak. 2001. A new concept in design of materials and structures: assemblies of interlocked tetrahedron-shaped elements. Scripta Materialia 44(12): 2689-2694.

Dyskin, Arcady V., Estrin, Yuri, Kanel-Belov, Alexei J. and Elena Pasternak. 2003. Topological interlocking of platonic solids: a way to new materials and structures. Philosophical Magazine Letters 83(3): 197-203.

Dyskin, Arcady V., Estrin, Yuri, Pasternak, Elena, Khor, Han C. and Alexei J. Kanel-Belov. 2005. The principle of topological interlocking in extraterrestrial construction. Acta Astronautica 57(1): $10-21$.

Eco, Umberto. 2000. Baudolino. Milan: Bompiani Editrice.

Estrin, Yuri. 2014. Topological interlocking and osteomorphic blocks. In: Stereotomic Design, eds. Giuseppe Fallacara and Vincenzo Minenna, 1-13. Maglie: Gioffreda Editore.

Estrin, Yuri, Dyskin, Arcady V. and Elena Pasternak. 2011. Topological interlocking as a material design concept. Materials Science and Engineering C 31(6): 1189-1194.

Etlin, Richard A. 2012. Stereotomy: The Paradox of an Acrobatic Architecture. In: Stereotomy: Stone Architecture and New Research, ed. Fallacara Giuseppe, 14-35. Paris: Presses des Ponts et Chaussées.

Etlin, Richard, Fallacara, Giuseppe and Luc Tamborero. 2008. Plaited Stereotomy - Stone Vaults for the Modern World. Rome: Aracne Editrice.

Fallacara, Giuseppe. 2003. Il paradigma stereotomico nell' arte del costruire: Dalla natura sincretica della modellazione digitale alla progettazione/costruzione di elementi architettonici in pietra da taglio. Ph.D. thesis, Politecnico di Bari.

Fallacara, Giuseppe. 2006. Digital stereotomy and topological transformations: reasoning about shape building. In: Proceedings of the Second International Congress on Construction History (Queen's College, Cambridge University, 29th March - 2nd April 2006), eds. M. Dunkeld, J. Campbell, H. J. Louw, M. Tutton, B. Addis, C. Powell, R. Thorne, 1075-1092. Cambridge: The Construction History Society.

Fallacara, Giuseppe. 2007. Verso una progettazione stereotomica. Nozioni di Stereotomia, Stereotomia digitale e trasformazioni topologiche: ragionamenti intorno alla costruzione della forma. Rome: Aracne Editrice.

Fallacara, Giuseppe. 2009. Toward a Stereotomic Design: Experimental Constructions and Didactic Experiences. In: Proceedings of the Third International Congress on Construction History (Brandenburg University of Technology, Cottbus, 20th-24th May 2009), ed. K. E. Kurrer, W. Lorenz and V. Wetzk, vol. 3, 553-559. Berlin: NEUNPLUS1.

Fallacara, Giuseppe. 2012. Stereotomy: Stone Architecture and New Research. Paris: Presses des Ponts et Chaussées.

Fallacara, Giuseppe. 2017. Topological Stereotomy in Architecture: origins and methods. Boletim da Aproged 33: 3-28.

Frézier, Amédée François. 1737-39. La théorie et la pratique de la coupe des pierres et des bois, pour la construction des voutes et autres parties des bâtimens civils \& militaires, 3 vols. Strasbourg, J.D. Doulksseker le fils. 
Mau, Bruce. 1998. An incomplete manifesto for growth. http://www.manifestoproject.it/bruce-mau (accessed 27 April 2018).

Merritt, Tim R. and Pedro de Azambuja Varela. 2014. Designing And Building The Cork Vault: Reflections On A Two-Week Digital Fabrication Workshop. In: DesignEd Asia, 1-11. http://www. designedasia.com/2014/Full_Papers/2014/24_Designing\%20and\%20building\%20the\%20cork\% 20vault.pdf. Accessed 10 Jan. 2018.

McGee, Wes, Feringa, Jelle and Asbjørn Søndergaard. 2013. Processes for an Architecture of Volume. In: Rob|Arch 2012: Robotic Fabrication in Architecture, Art and Design, ed. Sigrid Brell-Cokcan and Johannes Braumann, 62-71. Vienna: Springer-Verlag Wien.

Monge, Gaspard. 1798. Géométrie descriptive. Paris: Baudouin.

Pérouse de Montclos, Jean-Marie. 2001. L’Architecture à la française, du milieu du XVe à la fin du XVIIIe siècle. Paris: Picard.

Rabasa Díaz, Enrique. 1998. La bóveda plana de Abeilla en Lugo. In: II Congreso nacional de historia de la construcción (Instituto Juan de Herrera, CEHOPU, Universidad de la Coruña - Madrid, 22th-24th October 1998), ed. F. Bores, J. Fernández, S. Huerta, E. Rabasa, 409-415. Madrid: Instituto Juan de Herrera.

Rippmann, Matthias. 2016. Funicular Shell Design: Geometric approaches to form finding and fabrication of discrete funicular structures. Ph.D. thesis, ETH Zürich.

Rippmann, Matthias and Philippe Block. 2018. Computational Tessellation of Freeform, Cut-Stone Vaults. Nexus Network Journal 20(2). In press.

Sakarovitch, Joël. 2006. Construction history and experimentation. In: Proceedings of the Second International Congress on Construction History (Queen's College, Cambridge University, 29th March - 2nd April 2006), eds. M. Dunkeld, J. Campbell, H. J. Louw, M. Tutton, B. Addis, C. Powell, R.Thorne, 2777-2792. Cambridge: The Construction History Society.

Schwartz, Thibault and Lucia Mondardini. 2014. Integrated design and robotized prototyping of Abeille's vaults. In: Robotic Fabrication in Architecture, Art and Design 2014, ed. Wes McGee and Monica Ponce de Leon, 199-209. Cham: Springer International Publishing.

Torrini, Maurizio. 1993. Galileo copernicano. Giornale critico della filosofia italiana 13(1): $26-42$.

Tessmann, Oliver. 2012. Topological interlocking assemblies. In: Physical Digitality_Proceedings of the 30th International Conference on Education and Research in Computer Aided Architectural Design in Europe, 201-210. http://papers.cumincad.org/data/works/att/ecaade2012_176.content.pdf. Accessed 16 Jan. 2018.

Tessmann, Oliver. 2013. Interlocking Manifold Kinematically Constrained Multi-material Systems. In: Advances in Architectural Geometry 2012, eds. Lars Hesselgren, Shrikant Sharma, Johannes Wallner, Niccolo Baldassini and Philippe Bompas, 269-278. Vienna: Springer-Verlag Wien.

Tessmann, Oliver and Mirco Becker. 2013. Extremely heavy and incredibly light: performative assemblies in dynamic environments. In: 18th International Conference on Computer-Aided Architectural Design Research in Asia: Open Systems, CAADRIA 2013, 469-478. https://cumincad. architexturez.net/system/files/pdf/caadria2013_023.content.pdf. Accessed 16 Jan. 2018.

Trevisan, Camillo. 2009. Metodi e applicazioni tra la metà del Cinquecento e la metà del Settecento. In: Geometria Descrittiva. Volume II - Tecniche e applicazioni, ed. Riccardo Migliari, 523-561. Milan: Città Studi Edizioni.

Trevisan Camillo. 2011. Per la storia della stereotomia: geometrie, metodi e costruzioni. Rome: Aracne Editrice.

Uva, Giuseppina. 2003. Learning from traditional vaulted systems for the contemporary design. an updated reuse of flat vaults: Analysis of structural performance and recent safety requirements. In: Proceedings of the First International Congress on Construction History (Instituto Juan de Herrera, Madrid, 20th-24th January 2003), ed. Santiago Huerta, 2015-2021. Madrid: Instituto Juan de Herrera.

Varela de Azambuja, Pedro and José Pedro Sousa. 2018. Variable Casting of Voussoirs for a Stereotomic Shell. Nexus Network Journal 20(2). In press.

Giuseppe Fallacara is Associate Professor at the Politecnico di Bari, Department of Civil Engineering and Architecture, where he teaches Architectural Design and Stereotomy. He earned a Ph.D. in "Architectural Design for the Mediterranean countries" from Politecnico di Bari. His research is focused on the updating of the stone architecture, with particular theoretical and practical attention to Stereotomy. 
He published several scientific essays about the subject and he is author of numerous full-size prototypes and practical workshops related to the updating of stone architecture. He is head of the New Fundamental Research Group and Coordinator of the the C.E.S.AR. Course (Architecture and Restoration) of the Scuola di Specializzazione dei Beni Architettonici e del Paesaggio of the Politecnico di Bari. He has been Visiting Professor in several institutions: ENSA Paris-Malaquais, ETSAM Madrid, BME Budapest, ISCTE Lisboa, Monash University, MISIS Moskow and New York Institute of Technology.

Maurizio Barberio earned a Ph.D. in "Architecture: Innovation and Heritage" from the Politecnico di Bari and Università degli Studi Roma Tre. He currently teaches Architectural Design and Digital Fabrication in the C.E.S.AR. Course (Architecture and Restoration) of Scuola di Specializzazione dei Beni Architettonici e del Paesaggio of the Politecnico di Bari. His research concerns the areas of architectural design, architectural didactics, digital design and digital fabrication, with a specialization in the field of stone stereotomic architecture. In this regard he has co-designed and exhibited several built prototypes, published articles and presented papers at International Conferences. $\mathrm{He}$ is co-founder of the New Fundamentals Research Group and co-founder of the architecture firm Barberio Colella ARC. He is a licensed architect in Italy. 